\title{
HHLA2 and PD-L1 co-expression predicts poor prognosis in patients with clear cell renal cell carcinoma
}

\author{
Qiang-Hua Zhou, ${ }^{1,2}$ Kai-Wen Li, ${ }^{1,2}$ Xu Chen, ${ }^{1,2}$ Hai-Xia He, ${ }^{3,4}$ Sheng-Meng Peng, ${ }^{1,2}$ \\ Shi-Rong Peng, ${ }^{1,2}$ Qiong Wang, ${ }^{1,2}$ Ze-An Li, ${ }^{1,2}$ Yi-Ran Tao, ${ }^{1,2}$ Wen-Li Cai, ${ }^{5}$ \\ Ran-Yi Liu, ${ }^{3}$ Hai Huang (D) ${ }^{1,2}$
}

To cite: Zhou Q-H, Li K-W, Chen $\mathrm{X}$, et al. HHLA2 and PD-L1 co-expression predicts poor prognosis in patients with clear cell renal cell carcinoma. Journal for ImmunoTherapy of Cancer 2020;8:e000157. doi:10.1136/jitc-2019-000157

- Additional material is published online only. To view please visit the journal online (http://dx.doi.org/10.1136/jitc2019-000157).

Q-HZ, K-WL and XC contributed equally.

Accepted 16 December 2019

Check for updates

(C) Author(s) (or their employer(s)) 2020. Re-use permitted under CC BY. Published by BMJ.

For numbered affiliations see end of article.

Correspondence to Dr Hai Huang; huanghai257@126.com

Professor Ran-Yi Liu; liury@sysucc.org.cn

\section{ABSTRACT}

Background Although clear cell renal cell carcinoma (ccRCC) is well known as a highly immunogenic tumor, only a small subset of patients could benefit from current immunotherapy, which might be due to the heterogeneity of immune microenvironment in ccRCC. So, it is meaningful to explore novel immunotherapy or combination therapy for improving therapeutic efficacy. HHLA2, a newly discovered B7 family member, is prevalently expressed in numerous tumors, including ccRCC. This study aimed to investigate the prognostic impact of HHLA2/PD-L1 co-expression and its relationship with tumor-infiltrating lymphocytes (TILs).

Methods The expression levels of HHLA2, PD-L1, CD8, and CD4 in cancer tissues from cases (206 in the training cohort and 197 in the validation cohort) with surgically resectable primary ccRCC were evaluated by immunohistochemistry.

Results The positive rates of HHLA2 were much higher than those of PD-L1 in ccRCC tissues. HHLA2-positive expression was significantly associated with necrosis, microvascular invasion, advanced Fuhrman nuclear, and TNM stage and indicated a shorter progression-free survival (PFS) and overall survival (OS) in both cohorts. Moreover, patients with HHLA2/PD-L1 co-expression suffered the highest risk of disease progression and death by a significant margin. Besides, HHLA2/PD-L1 co-expression was significantly associated with a high density of $\mathrm{CD}^{+}$and $\mathrm{CD} 4^{+}$TILs. Notably, a new immune classification, based on HHLA2/PD-L1 co-expression and TILs, successfully stratified PFS and OS, especially in patients with TILS positivity.

Conclusions The expression of HHLA2 is more frequent than PD-L1 in ccRCC. HHLA2/PD-L1 co-expression had an adverse impact on the prognoses of patients with ccRCC; this finding provides a rationale for combination immunotherapy with anti-HHLA2 and PD-L1 blockage for patients with $\mathrm{CCRCC}$ in the future.

\section{BACKGROUND}

Clear cell renal cell carcinoma (ccRCG) represents the most common renal cell cancer (RCG), which accounts for $2 \%$ of the global cancer burden. ${ }^{1-3}$ In 2013 alone, $>140000$ patients, especially advanced patients, died due to either renal carcinoma or corresponding complications despite the development of multidisciplinary treatments for ccRCC (including radical or partial nephrectomy and targeted therapy). ${ }^{4}$ Therefore, there is a critical clinical need to develop innovative strategies to reverse poor clinical outcomes associated with current therapies in ccRCC.

Since the last century, Immunotherapy, such as anti-CTLA-4 antibody ${ }^{5}$ and anti-PD-1 antibody, ${ }^{6}$ has been regarded as a promising therapy for ccRCC due to its immunogenic nature. In particular, anti-programmed death 1 (PD-1) antibody nivolumab was approved by the Food and Drug Administration (FDA) because of a higher response rate and less frequent adverse events compared with mTOR inhibitor everolimus in a phase III trial. ${ }^{6}$ However, the objective response rates were only $25 \%-42 \%$ with nivolumab or even combined with ipilimumab (anti-CTLA-4) in advanced RCC, indicating alternative immunosuppressive checkpoints or pathways disrupting immunosurveillance in ccRCC. ${ }^{56}$ In this perspective, it is of great significance for the guidance of clinical immunotherapy to establish a suitable immunophenotyping system to predict patients who will respond to immune checkpoint blockades ${ }^{7}$.

According to the theory proposed by Teng et al, a tumor is classified into four groups based on the TIL density and programmed death 1 ligand 1 (PD-L1) expression, including adaptive immune resistance, immunological ignorance, tolerance, and intrinsic induction. ${ }^{8}$ Although this classification could provide guidance for immunotherapy, some misadvises would also arise as only PD-L1 but no other immunosuppressive checkpoints were included in the theory. Besides PD-L1, other negative regulatory co-stimulatory molecules including PD-L2 and B7-H3 were detected 
with high expression and associated with poor prognosis in ccRCC, whereas the positive rates of PD-L2 and B7-H3 were limited. ${ }^{9}{ }^{10}$ Furthermore, the expression of a PD-L1 and/or PD-L2 on tumor cells, as well as a low percentage of $\mathrm{CD} 8^{+} \mathrm{PD}-1^{+} \mathrm{T}$ cells might be valuable for predicting response to PD-1 blockade therapy in metastatic ccRCC. ${ }^{11}$ Simultaneous activation of $\mathrm{CD} 8^{+}$ $\mathrm{T}$ cells and PD-1 blockade provides more benefits for metastatic ccRCC. ${ }^{12}$ However, tumor-infiltrating naive CD4 $\mathrm{T}$ cells are associated with low responsiveness to PD-1 blockades. ${ }^{13}$ Collectively, the theory, mentioned previously, could not fully clarify the complexity of the immune microenvironment in ccRCC. Therefore, it will be of important clinical significance to optimize existing immune classifications by introducing new immunosuppressive checkpoints with a high positive rate in ccRCC.

Recently, increasing focus has turned to human endogenous retrovirus-H long terminal repeatassociating protein 2 (HHLA2, also known as B7-H7), a newly discovered member of the $\mathrm{B} 7$ family and analogous to PD-L1, PD-L2, and B7-H3. ${ }^{14}$ HHLA2 inhibits the proliferation and cytokine production of $\mathrm{CD}^{+}$and $\mathrm{CD}^{+} \mathrm{T}$ cells through binding to its putative receptors in a variety of immune cells. ${ }^{14}{ }^{15}$ To date, transmembrane and immunoglobulin domain containing protein 2 (TMIGD2) is the only evidenced receptor of HHLA2. ${ }^{16}$ As TMIGD2 is mainly expressed on naive $T$ cells but not mature $T$ cells, it would be possible that other undefined molecules are responsible for the immunosuppressive role of HHLA2. ${ }^{17}$ In addition, Rahimi et al reported that TMIGD2 was also detected in endothelial cells, therefore, HHLA2 may also have a potential role in tumor angiogenesis. ${ }^{18}$ Janakiram et al demonstrated that HHLA2 was widely expressed in cancer samples such as breast, lung, and prostate cancers. ${ }^{16}$ Moreover, HHLA2 was more prevalently expressed in various cancer cells than PD-L1 and HHLA2 overexpression was common in PD-L1negative breast cancer and cholangiocarcinoma. ${ }^{19} 20$ HHLA2 was also reported to be overexpressed in RCC, compared with normal renal tissue, and the expression of HHLA2 was associated with poor prognosis of RCC. ${ }^{21}{ }^{22}$ However, the relationship between HHLA2 and the immune microenvironment has not been uncovered in RCC.

In our present study, we evaluated the relationship between HHLA2 expression, clinicopathological features, and the immune microenvironment by analyzing date from two large cohorts. Then, we introduced HHLA2 expression status into the immune classification based on TIL density and PD-L1 expression to optimize the present immune classification and establish a novel immunophenotyping system. We then examined its clinical significance for ccRCC in two independent cohorts. This study may provide a useful guide for patients with ccRCC in choosing proper immunotherapy.
MATERIALS AND METHODS

\section{Patients and samples}

On approval by the Institutional Ethical Boards of Sun Yatsen University Cancer Center (SYSUCC) and Sun Yat-sen Memorial Hospital (SYMH), we retrospectively analyzed data from two cohorts: a training cohort from SYSUCC (206 patients) and a validation cohort from SYMH (197 patients). Patients in both cohorts underwent surgical resection for ccRCC from January 2006 to December 2013, and each patient signed informed consents. Patients who received neoadjuvant therapy were excluded from the present study. Formalin-fixed, paraffin-embedded (FFPE) blocks of all patients were collected from the pathology department and two senior pathologists were assigned to confirm Fuhrman nuclear grade, T stage and $\mathrm{N}$ status with $\mathrm{H} \& \mathrm{E}$ tumor slides, according to the American Joint Committee on Cancer (AJCC) 2009 TNM classification for ccRCC. Distant metastasis was evaluated by imaging examination. Progression-free survival (PFS) was defined as time span from the date of surgery to the date of cancer progression or death, and the overall survival (OS) was defined as time span from the date of surgery to the date of death. The follow-up was censored on 31 December 2018, the date of the last follow-up for patients without progression or death event.

\section{Immunohistochemistry}

Immunohistochemistry (IHC) staining for HHLA2, PD-L1, CD8, and CD4 was accomplished by a professional pathologist. $^{23-25}$ After deparaffinization, rehydration, antigen retrieval, endogenous peroxidase inactivation, and blocking non-specific binding, the $4 \mu \mathrm{M}$-thick sections were incubated with primary antibodies (anti-HHLA2: Sigma-Aldrich, HPA055478; anti-PD-L1: cell signaling technology, CST \#13684; anti-CD8: CST, \#85336; antiCD4: Abcam, ab252199) at $4^{\circ} \mathrm{C}$ overnight. Then, the slides were incubated with a corresponding secondary antibody and visualized by using a DAKO EnVision Detection System (Dako). Finally, the slides were counterstained with hematoxylin, dehydrated, and cover-slipped.

\section{Quantification of HHLA2, PD-L1 and infiltration of T cells}

HHLA2 and PD-L1 expressions on the tumor cell surface were evaluated based on the percentage of positive cells (eg, number of positive cells/ numbers of total cells). The optimal values for HHLA2 and PD-L1 expression were $20 \%$ and $10 \%$, respectively, which was calculated with $\mathrm{X}$-tlie. For CD8 and CD4 evaluation, the number of $\mathrm{CD} 8^{+}$ or $\mathrm{CD}^{+}$TILs was counted and averaged over five highpower fields for each case. ${ }^{26}$

\section{Statistical analysis}

The correlation analyses were performed using the $\chi^{2}$ test, whereas survival analysis was performed by the Kaplan-Meier method to depict the survival curves of PFS and OS. A log-rank test was carried out to examine intergroup differences. Univariate and multivariate analyses were executed via Cox proportional hazard model. 


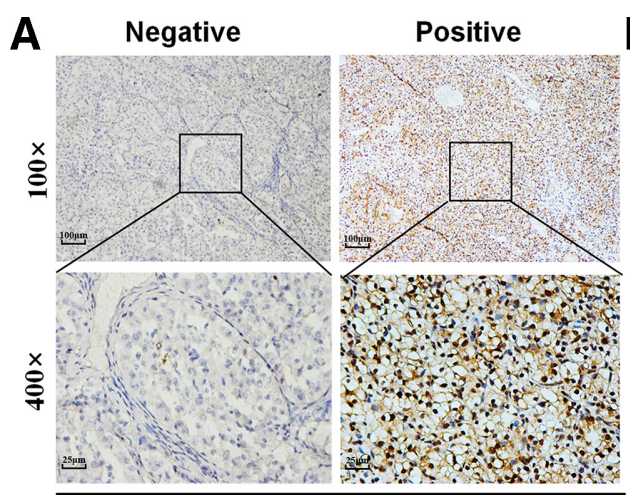

HHLA2
B Negative

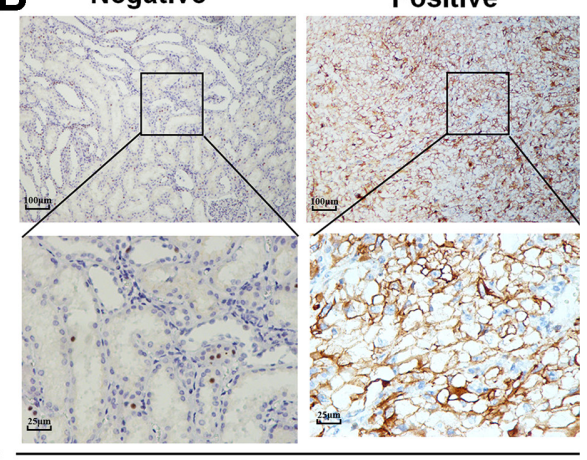

PD-L1

Figure 1 HHLA2 and PD-L1 expression in ccRCC tissue samples. Representative micrographs of HHLA2 (A) and PDL1 (B) expression within the tumor. ccRCC, clear cell renal cell carcinoma; HHLA2, human endogenous retrovirus-H long terminalrepeat-associating protein 2; PD-L1, programmed death 1 ligand 1.

All statistical analyses were accomplished by SPSS V.24.0 software and Graphpad Prism 7 software (La Jolla, California, USA). A $p$ value $<0.05$ was considered statistically significant.

\section{RESULTS}

\section{Patient characteristics}

The baseline patient clinicopathological characteristics of the two independent ccRCC cohorts are listed in the online supplementary table S1. In the training cohort, the median age at surgery was 53 years (ranging from 19 to 84 years). At the end of follow-up, $26.7 \%(55 / 206)$ patients had disease progression and $24.8 \%$ (51/206) patients died from ccRCC. The median PFS time was 47.7 months (ranging from 1 to 154 months) and the median OS time was 50.9 months (ranging from 1 to 154 months). In the validation cohort, the median age at surgery was also 53 years, (ranging from 21 to 80). At the end of follow-up, $30.5 \%(60 / 197)$ patients had disease progression and $27.4 \%$ (54/197) patients died from ccRCC. The median PFS was 57.6 months (ranging from 1 to 139 months) and the median OS was 61.3 months (ranging from 1 to 139 months).

Representative IHC photomicrographs for HHLA2 and PD-L1 in ccRCC are shown in figure 1. In both cohorts, the positive rates of HHLA2 expression were $44.2 \%$ (91/206) and $41.1 \%(81 / 197)$, which, interestingly enough, were significantly higher than the rates of PD-L1 expression at $33.0 \%(68 / 206)$ and $32.0 \%(63 / 197)$ (online supplementary table $\mathrm{S} 1$ ).

\section{Association of HHLA2 and PD-L1 expression with clinicopathological features}

The association between HHLA2 expression and clinicopathological characteristics is illustrated in table 1 . The HHLA2 positivity was significantly correlated with necrosis ( $\mathrm{p}=0.001$ for both cohorts), high Fuhrman grade (training cohort: $\mathrm{p}<0.001$; validation cohort: $\mathrm{p}=0.032$ ), and advanced TNM stage (training cohort: $\mathrm{p}<0.001$; validation cohort: $\mathrm{p}=0.008$ ) in both cohorts. Additionally, the HHLA2 positivity was associated with microvascular invasion (MVI) $(p=0.035)$ in the training cohort, but not in the validation cohort. This significant association was also detected between HHLA2 and PD-L1 expression in both cohorts (training cohort: $\mathrm{p}=0.003$; validation cohort: $\mathrm{p}=0.002$ ).

Similarly, in two cohorts, PD-L1 positivity was significantly associated with necrosis $(p=0.041$ and 0.001 , respectively), high Fuhrman grade ( $\mathrm{p}=0.002$ and 0.003 , respectively) and advanced TNM stage $(\mathrm{p}=0.003$ and 0.002 , respectively). A significant association between PD-L1 positivity and MVI was only identified in the training cohort $(\mathrm{p}<0.001)$ (online supplementary table S2).

\section{Impact of HHLA2 and PD-L1 expression on the progression- free survival and overall survival}

To explore the prognostic significance of HHLA2 and PD-L1, a univariate Cox proportional hazards regression was performed. HHLA2 (+) patients had significantly increased risks of disease progression and all causes of death compared with HHLA2 (-) patients (both in the training cohort (PFS: $\mathrm{HR}=3.23,95 \% \mathrm{CI}: 1.90$ to 5.50 , $\mathrm{p}<0.001$; OS: $\mathrm{HR}=3.98,95 \%$ CI: 2.15 to $7.37, \mathrm{p}<0.001$ ) and in the validation cohort (PFS: $\mathrm{HR}=2.17,95 \% \mathrm{CI}$ : 1.30 to 3.62 , $\mathrm{p}=0.003$, OS: $\mathrm{HR}=3.19,95 \%$ CI: 1.82 to 5.58 , $\mathrm{p}<0.001$ ) (table 2). Kaplan-Meier analysis revealed that HHLA2 positivity was significantly associated with worse PFS and OS in the training cohort (training cohort, PFS: $\mathrm{p}<0.001$; OS: $\mathrm{p}<0.001)$ and in the validation cohort (PFS: $\mathrm{p}<0.001$, OS: $\mathrm{p}<0.001$ ) (figure $2 \mathrm{~A}$ ).

In line with HHLA2, PD-L1 $(+)$ patients suffer much higher disease progression rates and mortality rates compared with PD-L1 (-) patients in both cohorts (PFS: $\mathrm{HR}=3.26,95 \% \mathrm{CI}: 1.91$ to $5.55, \mathrm{p}<0.001$; OS: $\mathrm{HR}=3.02$, 95\% CI: 1.73 to $5.24, \mathrm{p}<0.001$ in the training cohort, PFS: $\mathrm{HR}=2.77,95 \%$ CI: 1.66 to $4.61, \mathrm{p}<0.001$; OS: $\mathrm{HR}=2.92$, 95\% CI: 1.71 to $4.99, \mathrm{p}<0.001$ in the validation cohort) (table 2). Kaplan-Meier analysis also suggested that PD-L1 positivity was significantly associated with worse PFS and OS (figure 2B, training cohort, PFS: $p<0.001$, OS: $\mathrm{p}<0.001$; validation cohort, PFS: $\mathrm{p}<0.001$, OS: $\mathrm{p}<0.001)$. 
Table 1 The association of HHLA2 expression level with clinicopathological characteristics in the training cohort and validation cohort

\begin{tabular}{|c|c|c|c|c|c|c|c|c|}
\hline \multirow[b]{3}{*}{ Variables } & \multicolumn{4}{|c|}{ Training cohort $(n=206)$} & \multicolumn{4}{|c|}{ Validation cohort $(n=197)$} \\
\hline & \multirow[b]{2}{*}{ Patients, n } & \multicolumn{3}{|c|}{ HHLA2 expression } & \multirow[b]{2}{*}{ Patients, $\mathbf{n}$} & \multicolumn{3}{|c|}{ HHLA2 expression } \\
\hline & & Negative & Positive & $P$ value & & Negative & Positive & $P$ value \\
\hline Age (y) & & & & 0.619 & & & & 0.254 \\
\hline$<53$ & 90 & 52 & 38 & & 102 & 64 & 38 & \\
\hline$\geq 53$ & 116 & 63 & 53 & & 95 & 52 & 43 & \\
\hline Gender & & & & 0.409 & & & & 0.11 \\
\hline Male & 134 & 72 & 62 & & 141 & 88 & 53 & \\
\hline Female & 72 & 43 & 29 & & 56 & 28 & 28 & \\
\hline Necrosis & & & & 0.001 & & & & 0.001 \\
\hline Absent & 149 & 94 & 55 & & 151 & 99 & 52 & \\
\hline Present & 57 & 21 & 36 & & 46 & 17 & 29 & \\
\hline $\mathrm{MVI}$ & & & & 0.035 & & & & 0.148 \\
\hline Absent & 179 & 105 & 74 & & 169 & 103 & 66 & \\
\hline Present & 27 & 10 & 17 & & 28 & 13 & 15 & \\
\hline Fuhrman grade & & & & $<0.001$ & & & & 0.032 \\
\hline $\operatorname{Low}^{12}$ & 136 & 93 & 43 & & 129 & 83 & 46 & \\
\hline $\mathrm{High}^{34}$ & 70 & 22 & 48 & & 68 & 33 & 35 & \\
\hline TNM stage & & & & $<0.001$ & & & & 0.008 \\
\hline Low (I, II) & 146 & 94 & 52 & & 146 & 94 & 52 & \\
\hline High (III, IV) & 60 & 21 & 39 & & 51 & 22 & 29 & \\
\hline PD-L1 & & & & 0.003 & & & & 0.002 \\
\hline Negative & 138 & 87 & 51 & & 134 & 89 & 45 & \\
\hline Positive & 68 & 28 & 40 & & 63 & 27 & 36 & \\
\hline
\end{tabular}

${ }^{*} \mathrm{P}$ values $<0.05$ in bold are statistically significant.

HHLA2, human endogenous retrovirus-H long terminal repeat-associating protein 2; MVI, microvascular invasion; PD-L1, programmed death 1 ligand 1.

Furthermore, multivariate analysis showed that both HHLA2 and PD-L1 were independent predictors for PFS and $\mathrm{OS}$ in the training cohort (HHLA2, PFS: $\mathrm{HR}=2.10$, 95\% CI: 1.11 to $3.99, \mathrm{p}=0.023$, OS: $\mathrm{HR}=2.14,95 \% \mathrm{CI}$ : 1.11 to $4.15, \mathrm{p}=0.024$; PD-L1, PFS: $\mathrm{HR}=2.28,95 \% \mathrm{CI}$ : 1.30 to $3.99, \mathrm{p}=0.004$, OS: $\mathrm{HR}=2.27,95 \%$ CI: 1.26 to 4.09 , $\mathrm{p}=0.006$ ) (table 3). However, only HHLA2 was an independent predictor for PFS and OS in the validation cohort (HHLA2, PFS: HR=2.12, 95\% CI: 1.22 to $3.71, \mathrm{p}=0.008$, OS: $\mathrm{HR}=2.08,95 \%$ CI: 1.16 to $3.74, \mathrm{p}=0.014)$ (table 3 ).

\section{Co-expression of HHLA2 and PD-L1 in cCRCC and prognostic significance}

Considering that both HHLA2 and PD-L1 belong to the B7 family and both have an inhibitory function on $\mathrm{CD} 4^{+}$ or $\mathrm{CD}^{+} \mathrm{T}$ cells, we attempted to explore the prognostic impact of HHLA2/PD-L1 co-expression in ccRCC. In both cohorts, $40(19.4 \%)$ and $36(18.3 \%)$ patients were HHLA2 (+)/PD-L1 (+), $51(24.8 \%)$ and $45(22.8 \%)$ patients were HHLA2 (+)/PD-L1 (-), 28 (13.6\%) and $27(13.7 \%)$ patients were HHLA2 (-)/PD-L1 (+), and $87(42.2 \%)$ and $89(45.2 \%)$ patients were HHLA2 (-)/
PD-L1 (-), respectively (table 1). As Kaplan-Meier analysis demonstrated no significant difference for PFS and OS between patients with HHLA2 (+)/PD-L1 (-) and patients with HHLA2 (-) /PD-L1 (+) in both cohorts (online supplementary figure S1), patients were divided into three groups: group I, both negative (HHLA2 (-)/ PD-L1 (-)); group II, single positive (HHLA2 (+)/PD-L1 $(-)$ or HHLA2 $(-)$ /PD-L1 $(+))$; and group III, both positive (HHLA2 $(+) /$ PD-L1 $(+))$.

As illustrated in the online supplementary table S3, group III was closely associated with necrosis $(\mathrm{p}=0.001$ or $<0.001$ ) and advanced TNM stage (both $\mathrm{p}<0.001$ ) in the training and validation cohorts, and was additionally associated with MVI $(\mathrm{p}<0.001)$ and high Fuhrman grade $(p<0.001)$ in the training cohort. Kaplan-Meier analysis demonstrated that both PFS and OS in group III were significantly reduced compared with group I and group II in both cohorts (figure 2C). Importantly, multivariate analysis revealed that the HHLA2 (+)/PD-L1 (+) still had significant impact on PFS and OS (PFS: HR=2.29, 95\% CI: 1.53 to $3.41, \mathrm{p}<0.001$; OS: $\mathrm{HR}=2.31,95 \%$ CI: 1.52 to 3.50 , 
Table 2 Univariate analyses of prognostic factors correlated with PFS and OS

\begin{tabular}{|c|c|c|c|c|c|c|c|c|}
\hline \multirow[b]{3}{*}{ Variables } & \multicolumn{4}{|c|}{ Progression-free survival } & \multicolumn{4}{|l|}{ Over survival } \\
\hline & \multicolumn{2}{|l|}{ Training cohort } & \multicolumn{2}{|c|}{ Validation cohort } & \multicolumn{2}{|c|}{ Training cohort } & \multicolumn{2}{|c|}{ Validation cohort } \\
\hline & $\begin{array}{l}\text { HR } \\
(95 \% \mathrm{Cl})\end{array}$ & $P$ value & $\begin{array}{l}\text { HR } \\
(95 \% \mathrm{Cl})\end{array}$ & $\begin{array}{l}P \\
\text { value }\end{array}$ & HR (95\% Cl) & $\begin{array}{l}\mathbf{P} \\
\text { value } \\
\end{array}$ & $\begin{array}{l}\text { HR } \\
(95 \% \mathrm{Cl})\end{array}$ & $P$ value \\
\hline $\begin{array}{l}\text { Age }(y) \\
\geq 53 /<53\end{array}$ & $\begin{array}{l}1.251 \text { ( } 0.73 \text { to } \\
2.15)\end{array}$ & 0.415 & $\begin{array}{l}1.55 \text { (00.93 to } \\
2.59)\end{array}$ & 0.091 & $\begin{array}{l}1.57(0.89 \text { to } \\
2.80)\end{array}$ & 0.122 & $\begin{array}{l}1.58 \text { (0.92 to } \\
2.71)\end{array}$ & 0.096 \\
\hline $\begin{array}{l}\text { Gender } \\
\text { male/female }\end{array}$ & $\begin{array}{l}0.97(0.56 \text { to } \\
1.70)\end{array}$ & 0.926 & $\begin{array}{l}0.99(0.57 \text { to } \\
1.75)\end{array}$ & 0.986 & $\begin{array}{l}1.03 \text { (0.58 to } \\
1.82)\end{array}$ & 0.928 & $\begin{array}{l}1.19(90.67 \text { to } \\
2.11)\end{array}$ & 0.561 \\
\hline $\begin{array}{l}\text { Necrosis } \\
\text { present/absent }\end{array}$ & $\begin{array}{l}2.18(1.28 \text { to } \\
3.74)\end{array}$ & 0.004 & $\begin{array}{l}2.22(1.30 \text { to } \\
3.77)\end{array}$ & 0.003 & $\begin{array}{l}1.96(1.12 \text { to } \\
3.43)\end{array}$ & 0.018 & $\begin{array}{l}2.42(1.39 \text { to } \\
4.20)\end{array}$ & 0.002 \\
\hline $\begin{array}{l}\text { MVI } \\
\text { present/absent }\end{array}$ & $\begin{array}{l}2.97(1.62 \text { to } \\
5.46)\end{array}$ & $<0.001$ & $\begin{array}{l}3.46 \text { (1.98 to } \\
6.07)\end{array}$ & $<0.001$ & $\begin{array}{l}2.15(1.10 \text { to } \\
4.20)\end{array}$ & 0.024 & $\begin{array}{l}3.43(1.90 \text { to } \\
6.18)\end{array}$ & $<0.001$ \\
\hline $\begin{array}{l}\text { Fuhrman grade } \\
\text { high/low }\end{array}$ & $\begin{array}{l}3.97(2.30 \text { to } \\
6.85)\end{array}$ & $<0.001$ & $\begin{array}{l}3.45 \text { (2.06 to } \\
5.77)\end{array}$ & $<0.001$ & $\begin{array}{l}3.74(2.13 \text { to } \\
6.57)\end{array}$ & $<0.001$ & $\begin{array}{l}3.49 \text { (2.03 to } \\
6.02)\end{array}$ & $<0.001$ \\
\hline $\begin{array}{l}\text { TNM stage } \\
\text { high/low }\end{array}$ & $\begin{array}{l}7.92(4.46 \text { to } \\
14.08)\end{array}$ & $<0.001$ & $\begin{array}{l}3.77(2.27 \text { to } \\
6.25)\end{array}$ & $<0.001$ & $\begin{array}{l}7.14(3.98 \text { to } \\
12.83)\end{array}$ & $<0.001$ & $\begin{array}{l}3.93(2.30 \text { to } \\
6.19)\end{array}$ & $<0.001$ \\
\hline $\begin{array}{l}\text { HHLA2 } \\
\text { positive/negative }\end{array}$ & $\begin{array}{l}3.23(1.90 \text { to } \\
5.50)\end{array}$ & $<0.001$ & $\begin{array}{l}2.17 \text { (1.30 to } \\
3.62)\end{array}$ & 0.003 & $\begin{array}{l}3.98(2.15 \text { to } \\
7.37)\end{array}$ & $<0.001$ & $\begin{array}{l}3.19(1.82 \text { to } \\
5.58)\end{array}$ & $<0.001$ \\
\hline $\begin{array}{l}\text { PD-L1 positive/ } \\
\text { negative }\end{array}$ & $\begin{array}{l}3.26(1.91 \text { to } \\
5.55)\end{array}$ & $<0.001$ & $\begin{array}{l}2.77 \text { (1.66 to } \\
4.61)\end{array}$ & $<0.001$ & $\begin{array}{l}3.02(1.73 \text { to } \\
5.24)\end{array}$ & $<0.001$ & $\begin{array}{l}2.92(1.71 \text { to } \\
4.99)\end{array}$ & $<0.001$ \\
\hline
\end{tabular}

${ }^{*} P$ values $<0.05$ in bold are statistically significant.

HHLA2, human endogenous retrovirus-H long terminal repeat-associating protein 2; MVI, microvascular invasion; OS, overall survival; PD-L1, programmed death 1 ligand 1; PFS, progression-free survival.

$\mathrm{p}<0.001$ in the training cohort, PFS: $\mathrm{HR}=1.84,95 \% \mathrm{CI}$ : 1.28 to $2.65, \mathrm{p}=0.001$; OS: $\mathrm{HR}=1.86,95 \%$ CI: 1.26 to 2.74 , $\mathrm{p}=0.002$ in the validation cohort) (table 4 ).

\section{Relationship between HHLA2/PD-L1 co-expression and the infiltration of $\mathrm{CD}^{+} / \mathrm{CD8}^{+}$TILs in ccRCC}

As HHLA2 and PD-L1 expressions are induced by immunoregulatory factors mainly produced by TILs, we performed IHC to detect the density of $\mathrm{CD}_{4}^{+}$and $\mathrm{CD} 8^{+}$ TILs in ccRCC (figure 3A,B). As shown in figure 3C, the density of $\mathrm{CD}^{+}$TILs in the HHLA2 $(+)$tumors was significantly higher than that in HHLA2 $(-)$ tumors in both cohorts $(p<0.001)$. No significant association was found between $\mathrm{CD} 4^{+}$TILs and HHLA2 expression in the training cohort, whereas a positive association was detected between high HHLA2 expression and $\mathrm{CD}_{4}^{+}$ TILs in the validation cohort (figure 3C). There were higher densities of $\mathrm{CD}^{+}$and $\mathrm{CD} 4^{+}$TILs in PD-L1 (+) tumors compared with the PD-L1 (-) tumors (figure 3D). Furthermore, the infiltration of $\mathrm{CD}^{+}$(both $\mathrm{p}<0.01$ ) and $\mathrm{CD}^{+}$TILs $(\mathrm{p}<0.05$ or $<0.01)$ was strongest in group III (HHLA2 $(+)$ /PD-L1 $(+))$ in both the training and validation cohorts (figure $3 \mathrm{E}$ ).

\section{Immune classification for ccRCC}

Considering the important predictive value of HHLA2/ PD-L1 co-expression for both PFS and OS, and the significant correlation between HHLA2/PD-L1 co-expression and high density of TILs in ccRCC, we classified the patients into six types, based on TILs and HHLA2/PD-L1 co-expression, to provide rationale for immunotherapy.
Of the patients in both cohorts, $19.9 \%(41 / 206)$ and $22.8 \%(45 / 197)$ belong to type AI, defined as negative TILs and both negative (HHLA2 (-)/PD-L1 (-)); 12.7\% $(26 / 206)$ and $14.2 \%(28 / 197)$ belong to type AII, defined as negative TILs and single positive (HHLA2 (+)/PD-L1 $(-)$ or HHLA2 (-)/PD-L1 (+)); $1.9 \%(4 / 206)$ and $2.5 \%$ $(5 / 197)$ belong to type AIII, defined as negative TILs and both positive(HHLA2 (-)/PD-L1 (-)); 21.8\% (45/206) and $22.3 \%(44 / 197)$ belong to type BI, defined as positive TILs and both negative; $25.7 \%$ (53/206) and 22.3\% (44/197) belong to type BII, defined as positive TILs and single positive; $18.0 \%(37 / 206)$ and $15.0 \%(31 / 197)$ belong to type BIII, defined as negative TILs and both positive (online supplementary table S4). As shown in figure 2D, in the TILs-positive subgroups, Kaplan-Meier analysis demonstrated that both PFS and OS in group BIII were significantly reduced compared with group BI and group BII in both cohorts. However, in the TILsnegative subgroup, no significant difference for either PFS or OS was detected among the three groups (online supplementary figure S2).

\section{DISCUSSION}

HHLA2, a newly identified B7 family member, is widely expressed with positive rates ranging from $0 \%$ to $70 \%,{ }^{1627}$ and associated with poor prognosis in various cancers, such as lung cancer, cholangiocarcinoma, pancreatic carcinoma, and osteosarcoma. ${ }^{20}$ 27-29 Previous studies reported that high expression of HHLA2 was associated 
A

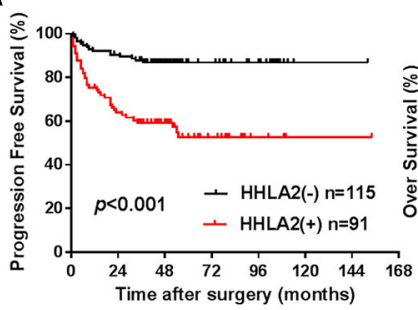

Training cohort

B

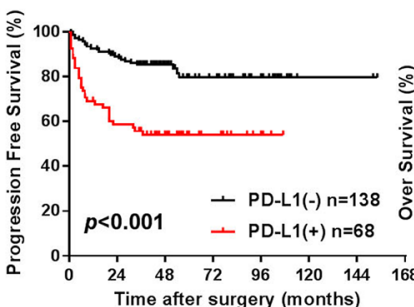

Training cohort

C
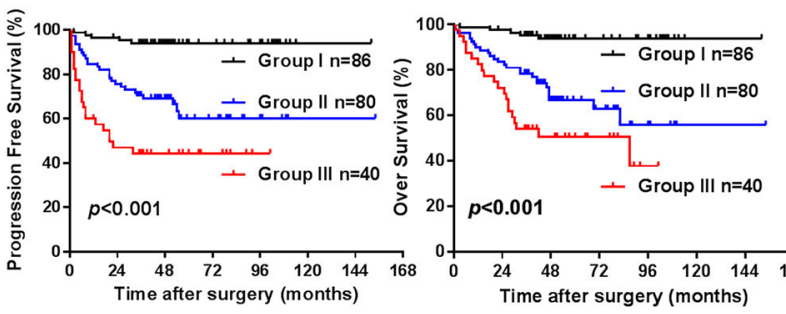

Training cohort

D
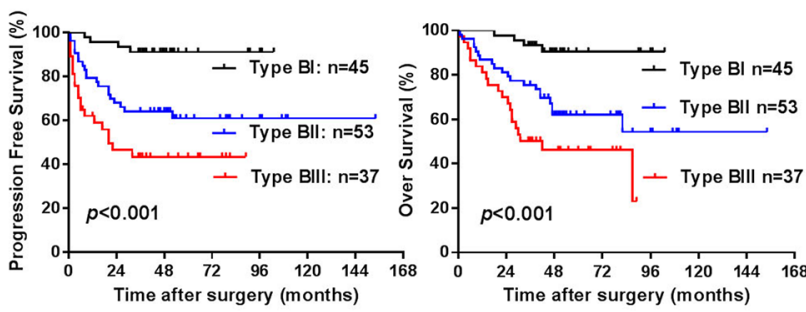

Training cohort
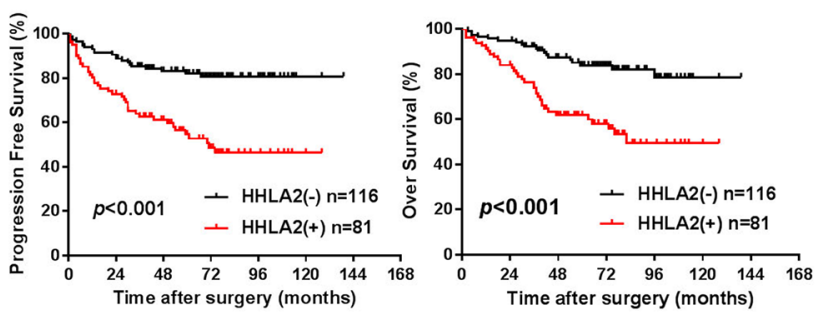

Validation cohort

.

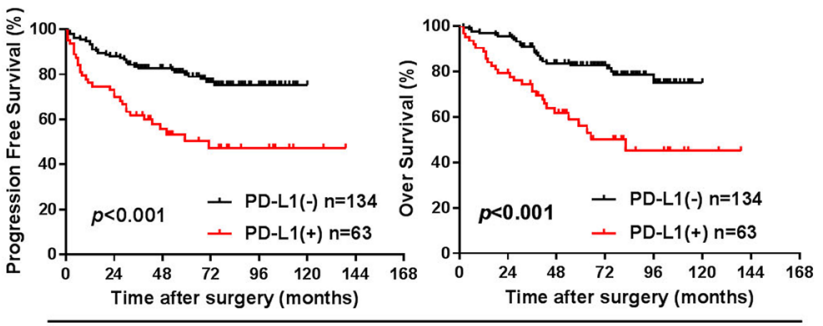

Validation cohort

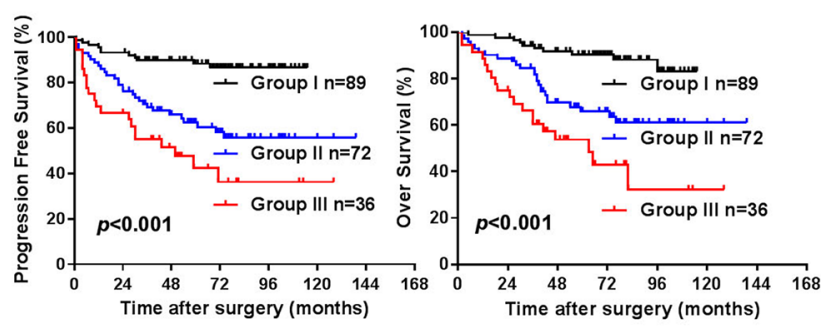

Validation cohort
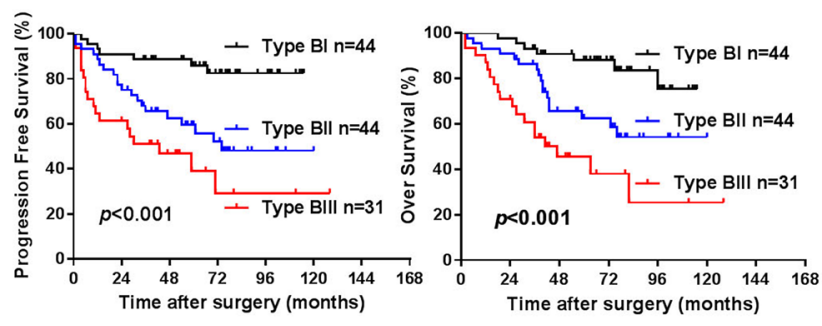

Validation cohort

Figure 2 Kaplan-Meier survival curves for PFS and OS of patients with ccRCC according to HHLA2 and PD-L1 expression. (A) PFS and OS according to HHLA2 expression status in the training cohort and validation cohort. (B) PFS and OS according to PD-L1 expression status in the training cohort and validation cohort. (C) PFS and OS according to a combination of HHLA2/ PD-L1 co-expression. Group I: HHLA2 (-)/PD-L1 (-); group II: HHLA2 (+)/PD-L1 (-) or HHLA2 (-)/PD-L1 (+); group III: HHLA2 $(+) / P D-L 1(+)$. (D) PFS and OS according to new immune classification. Type BI: TILs positive and both negative (HHLA2 (-)/ PD-L1 (-)); type Bll: TILs positive and single positive (HHLA2 (+)/PD-L1 (-) or HHLA2 (-)/PD-L1 (+)); type Blll: TILs positive and both positive (HHLA2(+)/PD-L1(+)). ccRCC, clear cell renal cell carcinoma; HHLA2, human endogenous retrovirus-H long terminalrepeat-associating protein 2; OS, overall survival; PD-L1, programmed death 1 ligand 1; PFS, progression-free survival; TIL, tumor-infiltrating lymphocyte.

with poor prognosis in ccRCC; moreover, high HHLA2 expression was an independent risk factor for the prognosis of ccRCC. ${ }^{21}{ }^{22}$ However, due to limited sample size,${ }^{21} 22$ especially in cases at the advanced clinical stage, ${ }^{21}$ these two studies could not provide sufficient evidence to completely illustrate the role of HHLA2 in the prognosis of patients with ccRCC. Herein, based on two large cohorts with 403 cases in total, we analyzed the expression pattern of HHLA2 and its clinical significance in ccRCC, and found that the positive rate of HHLA2 expression in ccRCC was over $40 \%$ and that of HHLA2 (+) was associated with shorter PFS and OS, in line with previous literature. Furthermore, high expression of HHLA2 was an independent prognostic factor in both cohorts after adjusting for necrosis, MVI, Fuhrman grade, and TNM stage. Notably, the expression of HHLA2 was more frequent than PD-L1, another renowned inhibitory costimulatory factor, consistent with prior literature,${ }^{152}$ which indicates 
Table 3 Multivariate analyses of prognostic factors correlated with PFS and OS

\begin{tabular}{|c|c|c|c|c|c|c|c|c|}
\hline \multirow[b]{3}{*}{ Variables } & \multicolumn{4}{|c|}{ Progression-free survival } & \multicolumn{4}{|l|}{ Over survival } \\
\hline & \multicolumn{2}{|l|}{ Training cohort } & \multicolumn{2}{|c|}{ Validation cohort } & \multicolumn{2}{|c|}{ Training cohort } & \multicolumn{2}{|l|}{ Validation cohort } \\
\hline & $\begin{array}{l}\text { HR } \\
(95 \% \mathrm{Cl}) \\
\end{array}$ & $\begin{array}{l}P \\
\text { value }\end{array}$ & $\begin{array}{l}\text { HR } \\
(95 \% \mathrm{Cl})\end{array}$ & $\begin{array}{l}P \\
\text { value }\end{array}$ & $\begin{array}{l}\text { HR } \\
(95 \% \mathrm{Cl}) \\
\end{array}$ & $P$ value & $\begin{array}{l}\text { HR } \\
(95 \% \mathrm{Cl})\end{array}$ & $\begin{array}{l}P \\
\text { value }\end{array}$ \\
\hline $\begin{array}{l}\text { Necrosis } \\
\text { present/absent }\end{array}$ & $1.00(0.55$ to 1.80$)$ & 0.995 & $\begin{array}{l}1.27(0.71 \text { to } \\
2.27)\end{array}$ & 0.429 & $\begin{array}{l}0.97(0.53 \text { to } \\
1.77)\end{array}$ & 0.911 & $1.35(0.73$ to 2.51$)$ & 0.335 \\
\hline $\begin{array}{l}\text { MVI } \\
\text { present/absent }\end{array}$ & 0.95 (0.48 to 1.88$)$ & 0.872 & $\begin{array}{l}1.64(0.90 \text { to } \\
2.99)\end{array}$ & 0.108 & $\begin{array}{l}0.58(0.27 \text { to } \\
1.25)\end{array}$ & 0.167 & $1.45(0.77$ to 2.76$)$ & 0.252 \\
\hline $\begin{array}{l}\text { Fuhrman grade } \\
\text { high/low }\end{array}$ & 1.45 (0.77 to 2.73$)$ & 0.251 & $\begin{array}{l}1.93(1.09 \text { to } \\
3.39)\end{array}$ & 0.023 & $\begin{array}{l}1.50(0.79 \text { to } \\
2.87)\end{array}$ & 0.217 & 2.04 (1.13 to 3.68$)$ & 0.018 \\
\hline $\begin{array}{l}\text { TNM stage } \\
\text { high/low }\end{array}$ & 5.14 (2.67 to 9.91$)$ & $<0.001$ & $\begin{array}{l}2.00(1.14 \text { to } \\
3.51)\end{array}$ & 0.016 & $\begin{array}{l}5.26(2.72 \text { to } \\
10.18)\end{array}$ & $<0.001$ & $2.02(1.10$ to 3.69$)$ & 0.023 \\
\hline $\begin{array}{l}\text { HHLA2 } \\
\text { positive/negative }\end{array}$ & 2.10 (1.11 to 3.99$)$ & 0.023 & $\begin{array}{l}2.12(1.22 \text { to } \\
3.71)\end{array}$ & 0.008 & $\begin{array}{l}2.14(1.11 \text { to } \\
4.15)\end{array}$ & 0.024 & 2.08 (1.16 to 3.74$)$ & 0.014 \\
\hline $\begin{array}{l}\text { PD-L1 } \\
\text { positive/negative }\end{array}$ & 2.28 (1.30 to 3.99$)$ & 0.004 & $\begin{array}{l}1.61 \text { (0.93 to } \\
2.77)\end{array}$ & 0.087 & $\begin{array}{l}2.27 \text { (1.26 to } \\
4.09)\end{array}$ & 0.006 & 1.66 (0.94 to 2.95$)$ & 0.081 \\
\hline
\end{tabular}

${ }^{*} P$ values $<0.05$ in bold are statistically significant.

HHLA2, human endogenous retrovirus-H long terminal repeat-associating protein 2; MVI, microvascular invasion; OS, overall survival; PD-L1, programmed death 1 ligand 1; PFS, progression-free survival.

that HHLA2 may be considered as a potential target for immunotherapy.

Although the expression of both PD-L1 and HHLA2 could be induced by immunoregulatory factors within the tumor microenvironment, the cells with HHLA2 $(+) /$ PD-L1 (+) are low (16\%) and quite part of the cases with PD-L1 negative contained a high expression of HHLA2 in lung cancer. ${ }^{15}$ Similarly, in our results, we found that the percentages of HHLA2 (+)/PD-L1 (+) were only $19.4 \%$ in the training cohort and $19.2 \%$ in the validation cohort, and $>30 \%$ of PD-L1 (-) cases have high expression of HHLA2. Considering the different distributions between HHLA2 and PD-L1 expression, we were the first to investigate the clinical significance of HHLA2 and PD-L1 co-expression in ccRCC. We found that HHLA2/PD-L1 co-expression was significantly associated with the TNM stage, which acted as an independent prognostic factor for shorter PFS and OS. These results provide some useful guidelines for immunotherapy: patients with HHLA2 (+)/ PD-L1 (+) may benefit from the dual blockade of PD-L1 and HHLA2; patients with one immune marker positive (PD-L1 or HHLA2) may need corresponding immune blockage to improve efficacy; for patients with no immune maker positive, the blockade of PD-L1 or HHLA2 may be inefficient and immunotherapy targeting another checkpoint, such as IDO1, TIM3, B7-H3, may be needed.

Table 4 Multivariate analyses of prognostic factors correlated with PFS and OS

\begin{tabular}{|c|c|c|c|c|c|c|c|c|}
\hline \multirow[b]{3}{*}{ Variables } & \multicolumn{4}{|c|}{ Training cohort } & \multicolumn{4}{|l|}{ Validation cohort } \\
\hline & \multicolumn{2}{|l|}{ PFS } & \multicolumn{2}{|l|}{ OS } & \multicolumn{2}{|l|}{ PFS } & \multicolumn{2}{|l|}{ OS } \\
\hline & $\begin{array}{l}\text { HR } \\
(95 \% \mathrm{Cl})\end{array}$ & $P$ value & $\begin{array}{l}\text { HR } \\
(95 \% \mathrm{CI})\end{array}$ & $\begin{array}{l}P \\
\text { value }\end{array}$ & $\begin{array}{l}\text { HR } \\
(95 \% \mathrm{Cl})\end{array}$ & $\begin{array}{l}P \\
\text { value }\end{array}$ & $\begin{array}{l}\text { HR } \\
(95 \% \mathrm{Cl})\end{array}$ & $\begin{array}{l}\mathbf{P} \\
\text { value }\end{array}$ \\
\hline $\begin{array}{l}\text { Necrosis } \\
\text { present/absent }\end{array}$ & $\begin{array}{l}0.99(0.55 \text { to } \\
1.79)\end{array}$ & 0.982 & $\begin{array}{l}0.96(0.53 \text { to } \\
1.76)\end{array}$ & 0.899 & 1.27 (0.71 to 2.28$)$ & 0.430 & $\begin{array}{l}1.36(0.74 \text { to } \\
2.53)\end{array}$ & 0.324 \\
\hline $\begin{array}{l}\text { MVI } \\
\text { present/absent }\end{array}$ & $\begin{array}{l}0.95 \text { (0.48 to } \\
1.87)\end{array}$ & 0.888 & $\begin{array}{l}0.58(0.28 \text { to } \\
1.23)\end{array}$ & 0.158 & 1.63 (0.89 to 2.98$)$ & 0.112 & $\begin{array}{l}1.44(0.76 \text { to } \\
2.72)\end{array}$ & 0.269 \\
\hline $\begin{array}{l}\text { Fuhrman grade } \\
\text { high/low }\end{array}$ & $\begin{array}{l}1.43(0.77 \text { to } \\
2.66)\end{array}$ & 0.265 & $\begin{array}{l}1.48 \text { (0.78 to } \\
2.81)\end{array}$ & 0.226 & 1.93 (1.09 to 3.40$)$ & 0.024 & $\begin{array}{l}2.04(1.12 \text { to } \\
3.69)\end{array}$ & 0.019 \\
\hline $\begin{array}{l}\text { TNM stage } \\
\text { high/low }\end{array}$ & $\begin{array}{l}5.06(2.64 \text { to } \\
9.72)\end{array}$ & $<0.001$ & $\begin{array}{l}5.19(2.69 \text { to } \\
10.01)\end{array}$ & $<0.001$ & 1.98 (1.13 to 3.49$)$ & 0.018 & $\begin{array}{l}2.00(1.09 \text { to } \\
3.67)\end{array}$ & 0.025 \\
\hline $\begin{array}{l}\text { HHLA2/PD-L1 } \\
\text { group III/II/I }\end{array}$ & $\begin{array}{l}2.29 \text { (1.53 to } \\
3.41)\end{array}$ & $<0.001$ & $\begin{array}{l}2.31 \text { (1.52 to } \\
3.50\end{array}$ & $<0.001$ & 1.84 (1.28 to 2.65$)$ & 0.001 & $\begin{array}{l}1.86(1.26 \text { to } \\
2.74)\end{array}$ & 0.002 \\
\hline
\end{tabular}

${ }^{*} P$ values $<0.05$ in bold are statistically significant.

HHLA2, human endogenous retrovirus-H long terminal repeat-associating protein 2; MVI, microvascular invasion; OS, overall survival; PD-L1, programmed death 1 ligand 1; PFS, progression-free survival. 

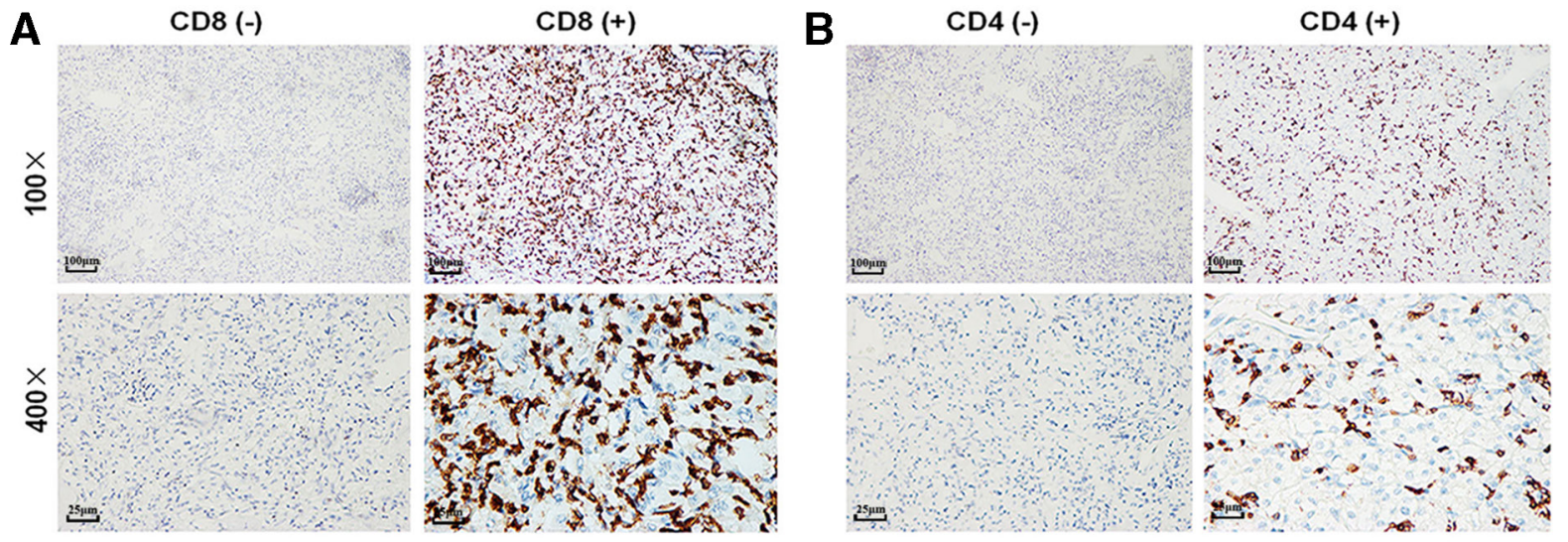

\section{C}
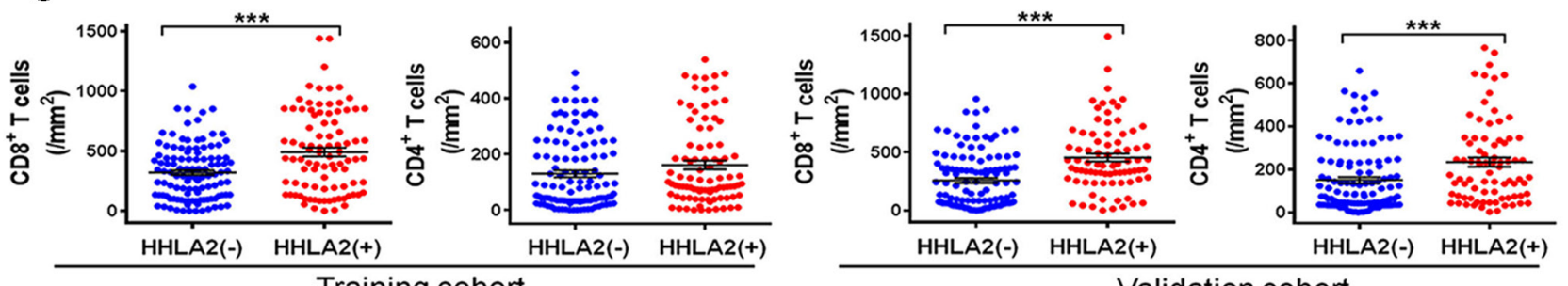

Training cohort

Validation cohort
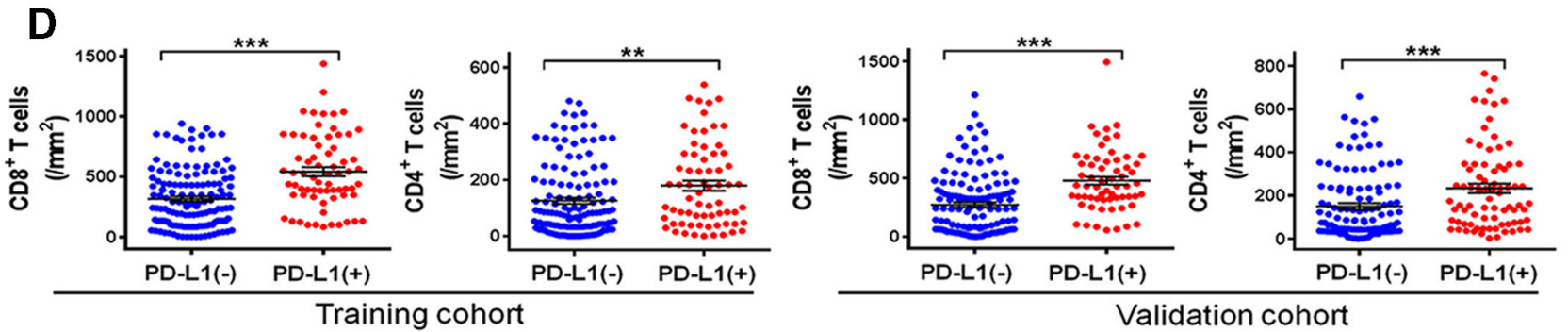

E
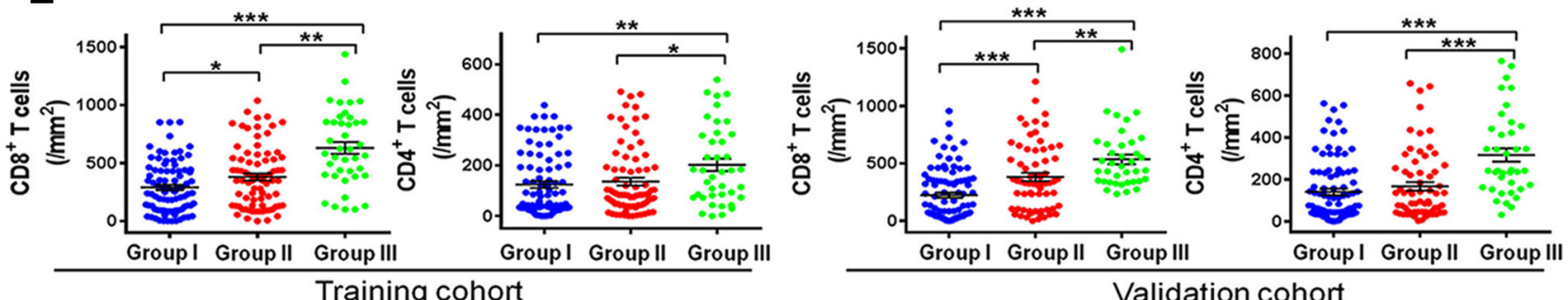

Figure 3 Representative micrographs of CD8 (A) and CD4 (B) expression and the corresponding negative controls within the tumor. Scatter plot depicted the correlation between HHLA2 and PD-L1 expression and classic subsets of T cells. (C) The correlation of HHLA2 expression and CD8 ${ }^{+}$T cells and CD4 ${ }^{+}$Tcells in the training cohort and validation cohort. (D) The correlation of PD-L1 expression and CD8 ${ }^{+}$T cells and $\mathrm{CD}^{+}{ }^{+}$Tcells in the training cohort and validation cohort. (E) The correlation of the HHLA2/PD-L1 co-expression and CD8 ${ }^{+}$T cells and CD4 ${ }^{+}$T cells in the training cohort and validation cohort. Group I: HHLA2 (-)/PD-L1 (-); group II: HHLA2 (+)/PD-L1 (-) or HHLA2 (-)/PD-L1 (+); group III: HHLA2 (+)/PD-L1 (+). HHLA2, human endogenous retrovirus-H long terminalrepeat-associating protein 2; PD-L1, programmed death 1 ligand 1.

Till now, the relationship between HHLA2 expression and immune cell infiltration in various cancers is still debatable. Cheng et al demonstrated that HHLA2 high expression was significantly associated with high TIL density in lung cancer, ${ }^{15}$ however, Koirala et al reported that no significant correlation was detected between HHLA2 expression and TILs in osteosarcoma. ${ }^{27}$ Furthermore, a negative association was observed between HHLA2 overexpression and cytotoxic $T$ cells. ${ }^{20}$ In renal cancer, Chen et al documented that there was no significant association between HHLA2 overexpression and the infiltrating intensity of $\mathrm{CD}^{+} \mathrm{T}$ cells, based on a small cohort of study. ${ }^{21}$ In the present study, we found that HHLA2 overexpression was significantly associated with a high density of $\mathrm{CD}^{+}$TILs, but not with the infiltration of $\mathrm{CD} 4^{+}$TILs. These data suggested that HHLA2 can be induced by interferon-gamma (IFN- $\gamma$ ) which mainly secreted by $\mathrm{CD}^{+}$TILs. Nevertheless, similar to PD-L1, HHLA2 could decrease both the $\mathrm{CD} 8^{+}$and $\mathrm{CD} 4^{+}$TILs proliferation and functionally inhibit the production of 
several cytokines, such as IFN- $\gamma$, tumor necrosis factoralpha, interleukin (IL)-5, IL-10, IL-13, and IL-17A. Therefore, through HHLA2 blockage, HHLA2(+) patients could benefit from immunotherapy.

According to Teng et al, a tumor is classified into four groups based on TIL density and PD-L1 expression, including: adaptive immune resistance, immunological ignorance, tolerance, and intrinsic induction. ${ }^{8}$ However, the feasibility of Teng's theory in ccRCC has not been confirmed. The expression of PD-L1 was not the most prevalent among B7 family members. For example, in PD-L1-negative lung cancer and cholangiocarcinoma, HHLA2 was more prevalent than PD-L1; and HHLA2 overexpression was common. ${ }^{1520}$ Therefore, this theory may overestimate the proportions of immunological ignorance and tolerance patterns, and inversely underestimate the proportion of adaptive immune resistance and intrinsic induction patterns. Hence, it may be much more rational to classify by TILs via the combination PD-L1 and HHLA2 or in combination with other B7 family members.

In this study, we classified patients with ccRCC into six groups based on HHLA2/PD-L1 co-expression and TILs. In this new classification, our results demonstrated that in TIL-positive groups, HHLA2/PD-L1 co-expression displayed significant prognostic value for PFS and OS; however, no significant difference for PFS and OS was detected in TIL-negative groups. These results suggested that both HHLA2 and PD-L1 perform immunosuppressive functions that mainly depend on suppression of the TILs function.

There are several limitations involved in this study. First, although we conducted a dual-center study based on a large number of cases, this was a retrospective study and the selection bias was inevitable. Second, we only combined HHLA2 and PD-L1 to conduct immune classification. Actually, other B7 family members, such as B7-H3 and B7x, or other immunosuppressive factors such as metabolites (eg, adenosine, IDO), also contribute to immunosuppression in the tumor microenvironment. ${ }^{30-32}$ Therefore, an immunophenotyping system containing other B7 family members is needed to guide clinical immunotherapy. Finally, because fewer patients were TIL negative, especially patients in type AIII subgroup, confirmation from a larger cohort is needed to determine whether HHLA2/PD-L1 co-expression displays no significant prognostic value for PFS and OS in TIL-negative groups.

\section{CONCLUSION}

Herein, we elucidated that HHLA2 expression was more prevalent than PD-L1 in ccRCC. HHLA2/PD-L1 co-expression was an independent predictor of poor prognosis, and these results may provide insight into effective strategies for combination therapy in ccRCC.

\section{Author affiliations}

${ }^{1}$ Department of Urology, Sun Yat-Sen Memorial Hospital, Sun Yat-sen University, Guangzhou, Guangdong, China

${ }^{2}$ Guangdong Provincial Key Laboratory of Malignant Tumor Epigenetics and Gene Regulation, Sun Yat-Sen Memorial Hospital, Sun Yat-Sen University, Guangzhou, Guangdong, China

${ }^{3}$ State Key Laboratory of Oncology in South China \& Collaborative Innovation Center of Cancer Medicine, Sun Yat-sen University Cancer Center, Guangzhou, Guangdong, China

${ }^{4}$ Department of Medical Oncology, Sun Yat-sen University Cancer Center, Guangzhou, China

${ }^{5}$ Department of Radiology, Massachusetts General Hospital, Harvard Medical School, Boston, Massachusetts, USA

Acknowledgements This work was supported by grants from Guangdong Science and Technology Department (2017B030314026). The authors would like to thank Dr Xinke Zhang and Dr Shumei Yan from Department of Pathology, SYSUCC for their assistance in IHC score.

Contributors Conception and design: $\mathrm{R}-\mathrm{YL}$ and $\mathrm{HH}$. Performing experiments: $\mathrm{Q}-\mathrm{HZ}$, K-WL. Drafting of the article: Q-HZ and XC. Acquisition and interpretation of data; review, editing and approval of the manuscript: all authors.

Funding This study was supported by the National Natural Science Foundation of China (81472382, 81672550, 81702523, 81702527 and 81974395), Guangdong Province Natural Science Foundation (2014A030313079, 2015A030310091, 2016A030313185), Guangdong Province Science and Technology for Social Development Project(2013B021800107 and 2017A020215018), Guangzhou City in 2015 scientific research projects (201510010298), International Science and technology cooperation project of Guangdong province science and technology plan (2016A050502020), Science and Technology Program of Guangzhou (Grant No. 201804010041), and China Scholarship Council to Hai Huang and Kaiwen Li.

Competing interests None declared.

Patient consent for publication Not required.

Ethics approval All patients signed an informed consent before surgery that permitted the usage of resected tumors and clinical profiles in research, under the condition of anonymity. The study was approved by the Clinical Research Ethic Committee of Sun Yat-sen University Cancer Center or Sun Yat-sen Memorial Hospital (SYSEC-KY-KS-2018-153).

Provenance and peer review Not commissioned; externally peer reviewed.

Data availability statement Data are available upon reasonable request. The datasets used and/or analysed during the current study are available from the corresponding author on reasonable request. The authenticity of this article has been validated by uploading the key raw data onto the Research Data Deposit public platform (http://rdd.sysucc.org.cn/), with the approval number RDDB2019000768.

Open access This is an open access article distributed in accordance with the Creative Commons Attribution 4.0 Unported (CC BY 4.0) license, which permits others to copy, redistribute, remix, transform and build upon this work for any purpose, provided the original work is properly cited, a link to the licence is given, and indication of whether changes were made. See https://creativecommons.org/ licenses/by/4.0/.

\section{ORCID iD}

Hai Huang http://orcid.org/0000-0002-2013-073X

\section{REFERENCES}

1 Turajlic S, Swanton C, Boshoff C. Kidney cancer: the next decade. J Exp Med 2018;215:2477-9.

2 Shuch B, Amin A, Armstrong AJ, et al. Understanding pathologic variants of renal cell carcinoma: distilling therapeutic opportunities from biologic complexity. Eur Urol 2015;67:85-97.

3 Barata PC, Rini BI. Treatment of renal cell carcinoma: current status and future directions. CA Cancer J Clin 2017;67:507-24.

4 Capitanio U, Montorsi F. Renal cancer. The Lancet 2016;387:894-906.

5 Hammers HJ, Plimack ER, Infante JR, et al. Safety and efficacy of nivolumab in combination with ipilimumab in metastatic renal cell carcinoma: the CheckMate 016 study. JCO 2017;35:3851-8. 
6 Motzer RJ, Escudier B, McDermott DF, et al. Nivolumab versus everolimus in advanced renal-cell carcinoma. $N$ Engl $\mathrm{J}$ Med 2015;373:1803-13.

7 Chinese Journal of Cancer. The 150 most important questions in cancer research and clinical oncology series: questions 57-66 : Edited by Chinese Journal of Cancer. Chin J Cancer 2017;36:79.

8 Teng MWL, Ngiow SF, Ribas A, et al. Classifying cancers based on T-cell infiltration and PD-L1. Cancer Res 2015;75:2139-45.

9 Shin S-J, Jeon YK, Kim P-J, et al. Clinicopathologic analysis of PDL1 and PD-L2 expression in renal cell carcinoma: association with oncogenic proteins status. Ann Surg Oncol 2016;23:694-702.

10 Crispen PL, Sheinin Y, Roth TJ, et al. Tumor cell and tumor vasculature expression of $\mathrm{B} 7-\mathrm{H} 3$ predict survival in clear cell renal cell carcinoma. Clin Cancer Res 2008;14:5150-7.

11 Pignon J-C, Jegede O, Mahoney KM, et al. Impact of immune checkpoint protein expression in tumor cells and tumor infiltrating $\mathrm{CD} 8{ }^{+} \mathrm{T}$ cells on clinical benefit from PD- 1 blockade in metastatic clear cell renal cell carcinoma (mccRCC). Journal of Clinical Oncology 2017;35:477.

12 Naing A, Wong DJ, Infante JR, et al. Pegilodecakin combined with pembrolizumab or nivolumab for patients with advanced solid tumours (ivy): a multicentre, multicohort, open-label, phase 1B trial. Lancet Oncol 2019;20:1544-55.

13 Juliá EP, Mandó P, Rizzo MM, et al. Peripheral changes in immune cell populations and soluble mediators after anti-PD-1 therapy in non-small cell lung cancer and renal cell carcinoma patients. Cancer Immunol Immunother 2019;68:1585-96.

14 Zhao R, Chinai JM, Buhl S, et al. HHLA2 is a member of the B7 family and inhibits human CD4 and CD8 T-cell function. Proc Natl Acad Sci U S A 2013;110:9879-84.

15 Cheng $\mathrm{H}$, Borczuk $\mathrm{A}$, Janakiram $\mathrm{M}$, et al. Wide expression and significance of alternative immune checkpoint molecules, B7x and HHLA2, in PD-L1-Negative human lung cancers. Clin Cancer Res 2018;24:1954-64.

16 Janakiram M, Chinai JM, Fineberg S, et al. Expression, clinical significance, and receptor identification of the newest B7 family member HHLA2 protein. Clin Cancer Res 2015;21:2359-66.

17 Zhu Y, Yao S, lliopoulou BP, et al. B7-H5 costimulates human T cells via CD28H. Nat Commun 2043;2013:4.

18 Rahimi N, Rezazadeh K, Mahoney JE, et al. Identification of IGPR-1 as a novel adhesion molecule involved in angiogenesis. Mol Biol Cell 2012;23:1646-56.

19 Janakiram M, Shah UA, Liu W, et al. The third group of the B7-CD28 immune checkpoint family: HHLA2, TMIGD2, B7x, and B7-H3. Immunol Rev 2017;276:26-39.
20 Jing C-Y, Fu Y-P, Yi Y, et al. HHLA2 in intrahepatic cholangiocarcinoma: an immune checkpoint with prognostic significance and wider expression compared with PD-L1. J Immunother Cancer 2019;7:77.

21 Chen L, Zhu D, Feng J, et al. Overexpression of HHLA2 in human clear cell renal cell carcinoma is significantly associated with poor survival of the patients. Cancer Cell Int 2019;19:101.

22 Chen D, Chen W, Xu Y, et al. Upregulated immune checkpoint HHLA2 in clear cell renal cell carcinoma: a novel prognostic biomarker and potential therapeutic target. J Med Genet 2019;56:43-9.

23 Xie R, Chen X, Chen Z, et al. Polypyrimidine tract binding protein 1 promotes lymphatic metastasis and proliferation of bladder cancer via alternative splicing of Meis2 and PKM. Cancer Lett 2019;449:31-44.

24 Zhou Q-H, Deng C-Z, Chen J-P, et al. Elevated serum LAMC2 is associated with lymph node metastasis and predicts poor prognosis in penile squamous cell carcinoma. Cancer Manag Res 2018;10:2983-95.

25 Chen X, Xie R, Gu P, et al. Long Noncoding RNA LBCS Inhibits Self-Renewal and Chemoresistance of Bladder Cancer Stem Cells through Epigenetic Silencing of SOX2. Clin Cancer Res 2019;25:1389-403.

26 Kawakami F, Sircar K, Rodriguez-Canales J, et al. Programmed cell death ligand 1 and tumor-infiltrating lymphocyte status in patients with renal cell carcinoma and sarcomatoid dedifferentiation. Cancer 2017; 123:4823-31.

27 Koirala P, Roth ME, Gill J, et al. HHLA2, a member of the B7 family, is expressed in human osteosarcoma and is associated with metastases and worse survival. Sci Rep 2016;6:31154.

28 Cheng $\mathrm{H}$, Janakiram $\mathrm{M}$, Borczuk $\mathrm{A}$, et al. HHLA2, a new immune checkpoint member of the B7 family, is widely expressed in human lung cancer and associated with EGFR mutational status. Clin Cancer Res 2017;23:825-32.

29 Yan H, Qiu W, Koehne de Gonzalez AK, et al. HHLA2 is a novel immune checkpoint protein in pancreatic ductal adenocarcinoma and predicts post-surgical survival. Cancer Lett 2019;442:333-40.

30 Stagg J, Smyth MJ. Extracellular adenosine triphosphate and adenosine in cancer. Oncogene 2010;29:5346-58.

31 Yao Y, Ye H, Qi Z, et al. B7-H4(B7x)-Mediated Cross-talk between Glioma-Initiating Cells and Macrophages via the IL6/JAK/STAT3 Pathway Lead to Poor Prognosis in Glioma Patients. Clin Cancer Res 2016;22:2778-90.

32 Munn DH, Mellor AL. Ido in the tumor microenvironment: inflammation, counter-regulation, and tolerance. Trends Immunol 2016;37:193-207. 


\section{Correction: HHLA2 and PD-L1 co-expression predicts poor}

\section{prognosis in patients with clear cell renal cell carcinoma}

Zhou Q, Li K, Chen X, et al. HHLA2 and PD-L1 co-expression predicts poor prognosis in patients with clear cell renal cell carcinoma. J ImmunoTherap Cancer 2020;8:e000157. doi: 10.1136/jitc-2019-000157

In this article, the last panels in figure $3 \mathrm{C}$ and $3 \mathrm{D}$ incorrectly show the same image. The corrected figure 3 is shown below
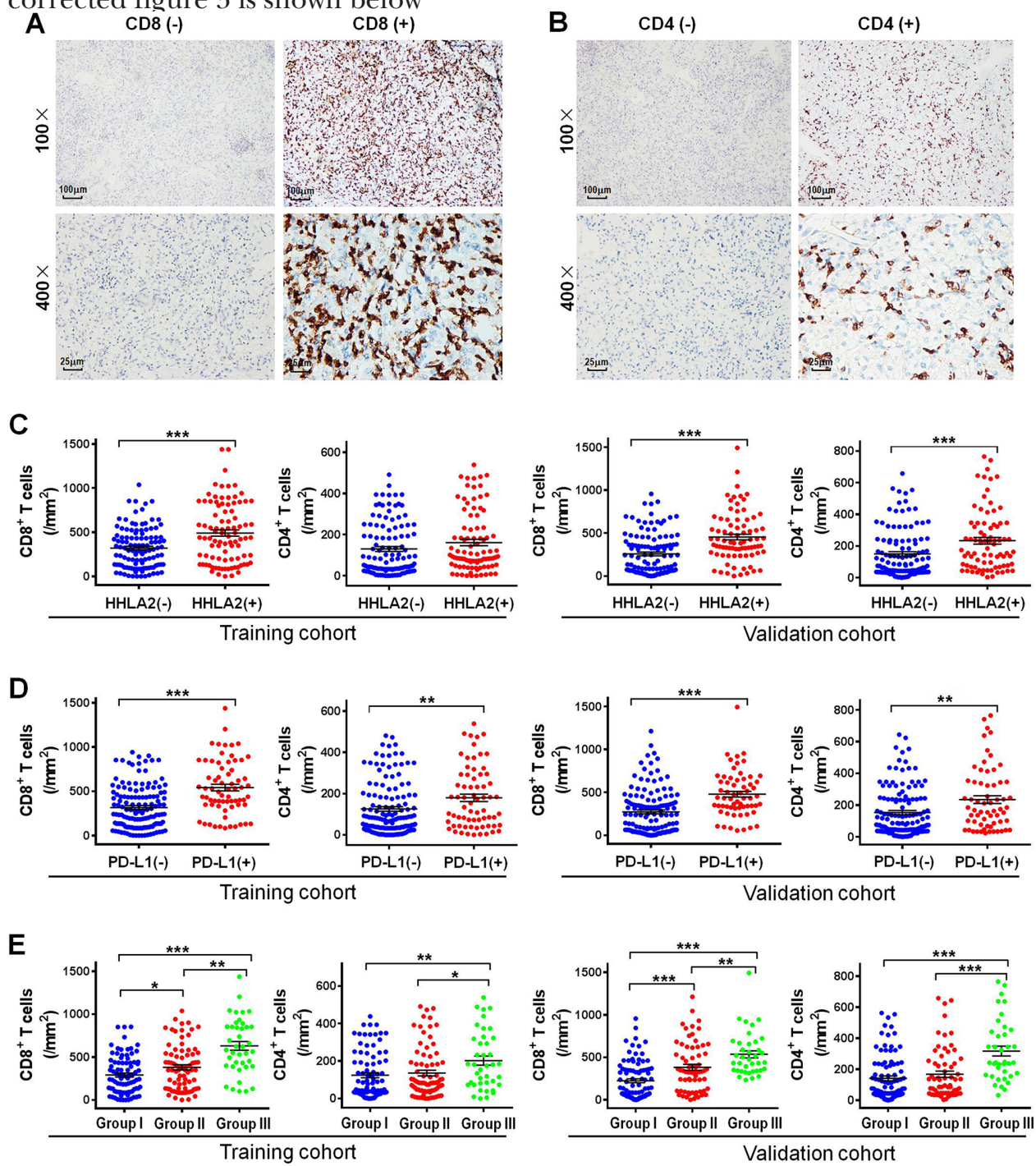

Figure 3. Representative micrographs of CD8 (A) and CD4 (B) expression and the corresponding negative controls within the tumor. Scatter plot depicted the correlation between HHLA2 and PD-L1 expression and classic subsets of T cells. (C) The correlation of HHLA2 expression and CD8+ Tcells and CD4+ Tcells in the training cohort and validation cohort. (D) The correlation of PD-L1 expression and CD8+ T cells and CD4+ T cells in the training cohort and validation cohort. (E) The correlation of the HHLA2/PD-L1 co-expression and CD8+ Tcells and CD4+ Tcells in the training cohort and validation cohort. Group I: HHLA2 (-)/PD-L1 (-); group II: HHLA2 (+)/PD-L1 (-) or HHLA2 (-)/PD-L1 (+); group III: HHLA2 (+)/PD-L1 (+). HHLA2, human endogenous retrovirus-H long terminal repeat-associating protein 2; PD-L1, programmed death 1 ligand 1.

Additionally, in the Results section titled 'Immune classification for ccRCC' the sentence " $1.9 \%(4 / 206)$ and $2.5 \%$ (5/197) belong to type AIII, defined as negative 
TILs and both positive(HHLA2 (-)/PD-L1 (-)); 21.8\% (45/206) and 22.3\% (44/197) belong to type BI, defined as posi- tive TILs and both negative; $25.7 \%(53 / 206)$ and $22.3 \%$ (44/197) belong to type BII, defined as positive TILs and single positive; $18.0 \%$ $(37 / 206)$ and $15.0 \%(31 / 197)$ belong to type BIII, defined as negative TILs and both positive (online supplementary table 4$)$ " should read " $1.9 \%(4 / 206)$ and $2.5 \%(5 / 197)$ belong to type AIII, defined as negative TILs and both positive(HHLA2 $(+) /$ PD-L1 $(+))$; $21.8 \%(45 / 206)$ and $22.3 \%$ (44/197) belong to type BI, defined as posi- tive TILs and both negative; $25.7 \%$ (53/206) and 22.3\% (44/197) belong to type BII, defined as positive TILs and single positive; $18.0 \%(37 / 206)$ and $15.0 \%(31 / 197)$ belong to type BIII, defined as positive TILs and both positive (online supplementary table 4)."

Open access This is an open access article distributed in accordance with the Creative Commons Attribution 4.0 Unported (CC BY 4.0) license, which permits others to copy, redistribute, remix, transform and build upon this work for any purpose, provided the original work is properly cited, a link to the licence is given, and indication of whether changes were made. See https://creativecommons.org/licenses/by/4.0/.

(C) Author(s) (or their employer(s)) 2020. Re-use permitted under CC BY. Published by BMJ.

J Immunother Cancer 2020;8:e000157corr1 . doi:10.1136/jitc-2019-000157corr1 